\title{
Defense Institution Building: Training in Support of Defense Planning
}

\section{Hari Bucur-Marcu and Cătălin-Marius Târnăcop *}

Training for senior officials is always a problem of high complexity, and training on defense issues is even more complex, for several reasons. Defense is becoming an increasingly specialized field, with a wide array of professional instruments, especially in the area of planning, but it lacks the concreteness of other public domains, such as health or education, as the success of good governance in national defense reveals itself only under special conditions.

Senior-level trainees exposed to new defense planning approaches come to their training experience with a wide array of knowledge and experience, and they are skilful in handling complex issues. Some of their skills, knowledge, and experience are of great value in introducing new topics, but other elements of their background may bias them in properly understanding the depth of those new topics. Their seniority also implies that their attention span and their learning curves are different than those of young and fresh students. Senior officials seldom are able to dedicate themselves full-time to training. Usually, training is only a part, and not necessarily the most important one, of their professional agenda. When the training is of an international nature, the trainees are of different backgrounds and cultures, and establishing a common denominator that fits every one of them may result in significant lapses of practical knowledge if the training process is not handled wisely.

Taking into account all those aspects, designing an interactive training course for senior officials on national defense policy with an emphasis on defense planning proved to be a very challenging task for the team at NATO Studies Center in Bucharest when we were asked to conduct such an event for a group of international participants at a conference in Tbilisi, Georgia, in April 2005. ${ }^{1}$ This article is an attempt to take stock of the experiences gained through planning that training program, and it proposes some general themes of reflection on training senior officials in support of defense planning. The first part presents a theoretical framework, with some considerations regarding defense planning that we thought any trainees should be aware of when embarking on a training program dealing with defense policy formulation and implemen-

* Dr. Hari Bucur-Marcu is the Academic Coordinator of the NATO Studies Center in Bucharest, Romania. Dr. Cătălin-Marius Târnăcop is a colonel in the Romanian Armed Forces and Associate Professor at the National Defense University in Bucharest, Romania.

1 On 26, 27, and 28 April 2005, the NATO Studies Center conducted an interactive training module on National Defense Policy within the Training Course on Partnership Action PlanDefense Institution Building (PAP-DIB) in Tbilisi, Georgia. The course and the preceding one-day conference were a joint Georgian-Swiss initiative with the support of the NATO International Secretariat, the Geneva Centre for the Democratic Control of Armed Forces (DCAF), and the NATO Studies Center (NSC). The Romanian Ministry of Foreign Affairs and Ministry of Defense supported NSC participation in the course. 
tation in an accountable and transparent manner. The second part of the essay captures the experience of training interactively on defense planning within the context of defense institution building.

\section{The Theoretical Framework}

Transforming the defense establishment and the war-fighting capabilities of any armed forces will remain a major strategic issue for many nations for the rest of the decade and beyond. Many defense officials have come to believe that defense transformation is necessary for success in the war on terror, and it remains an integral part of their military strategy. This approach was augmented with an expressed interest in a revolution in military affairs that would transform concepts, military capabilities, people, and organizations, and a supporting revolution in business affairs that would transform defense planning and resource allocation processes. ${ }^{2}$ Any nation that embarks on the process of defense institution building may derive great benefit from the theoretical framework developed in this context, and may gain some practical solutions for introducing arrangements and procedures to assess security risks and national defense requirements in a transparent and accountable manner. Those arrangements and procedures dealing with security risks and national defense requirements are based upon underlying principles, processes, and some general management requirements.

The general framework of discussion in such a course of training should be that of national defense policy. Defense policy involves the political direction of a nation's defense resources as a whole with a view to ensuring national security, protecting vital interests, and furthering the international aims of the state. There are at least two theoretical approaches to defense policy when that policy involves major changes such as a strategic review or transformation or defense institution building.

One theoretical approach is hierarchical, and the other one is holistic. Both are based on the principle that the defense sector is part of the broader security architecture of a nation. These approaches are not mutually exclusive, and in practice both are present in defense governance, but, as each may be reflected in a separate model, we prefer to discuss them separately at the theoretical level. The hierarchical model underlines the responsibilities across all governmental bodies involved in the formulation and implementation of defense policy and describes the steps that lead to the development of an efficient, affordable, and transparent defense. The holistic model, on the other hand, focuses solely on the interrelations between different security sectors.

\section{The Hierarchical Approach to Defense Policy Formulation and Implementation}

The hierarchy of national security and defense is depicted in Figure 1. National security strategy may be defined as the art and science of developing and using the political, economic, and psychological powers of a nation, together with its armed forces,

2 Christopher J. Lamb, Transforming Defense (Washington, D.C.: National Defense University Press, September 2005), 1-3. 
during times of peace and war, to secure national objectives. ${ }^{3}$ The head of state should present a National Security Strategy (1) to the parliament within several months of his or her assignment or election. The National Security Strategy represents a middle-term assessment of four to five years, with a perspective on long-term consequences.

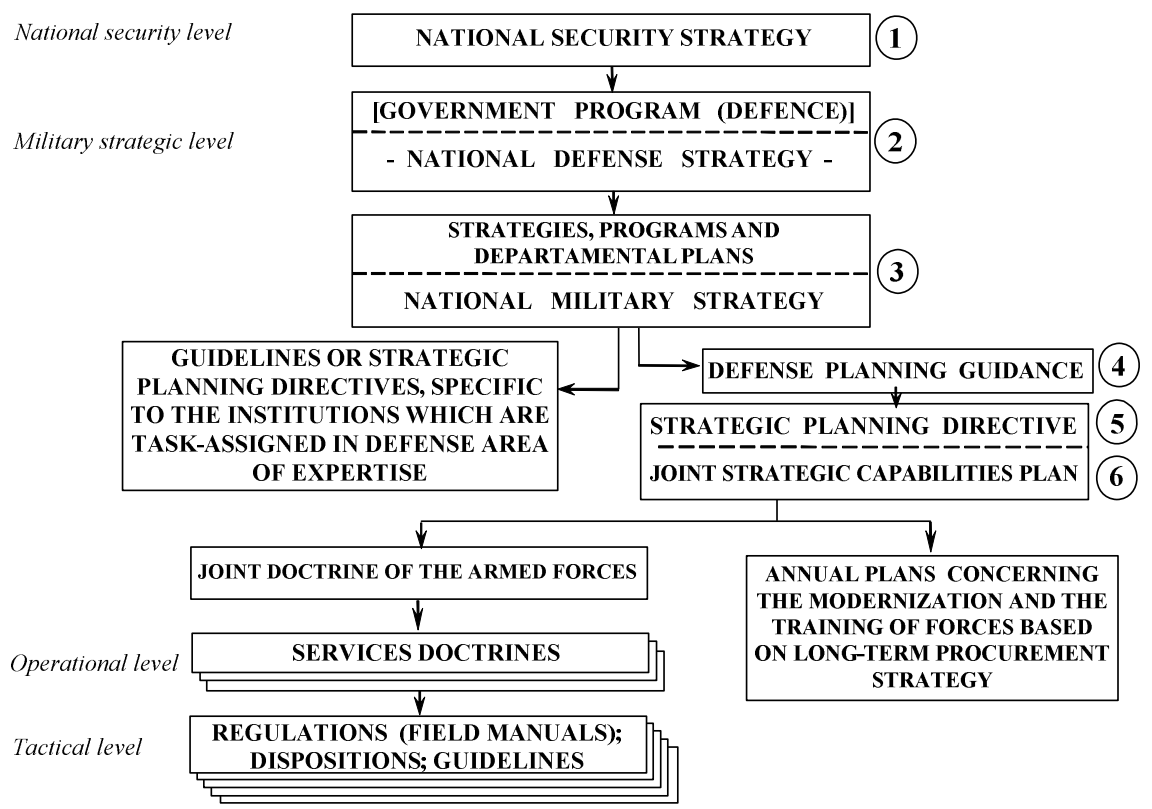

(c) Dr. CMTARNACOP

Figure 1: National Security and Defense Hierarchy

The governmental approach (2) to defense issues may take many forms, and materializes in one or several documents, such as a defense white paper, a government program, or a national defense strategy. The format and number of such documents depend on the way the government establishes executive tasks in order to accomplish national defense and security objectives, underline solutions to strategic issues, and to allocate the available resources through defining "a broad course of action or statements of guidance adopted by the government at the national level in pursuit of national objectives." ${ }^{4}$ Usually, the program, defense white paper, or national defense strategy are submitted to the legislative body for approval within several months of the election of the head of state. This document generally follows the same timelines as the National Security Strategy.

3 Colonel (Ret.) Arthur F. Lykke, Jr., "Defining Military Strategy,” Military Review (JanuaryFebruary 1997): 183-86.

4 Ibid., 183. 
The next hierarchical level (3) includes strategies, programs, and departmental plans at the ministerial level; in Figure 1, we have highlighted the National Military Strategy. Military strategy reflects the objectives and missions derived from higher-order strategies, such as the National Security Strategy and the National Defense Strategy, or even longer-term strategic documents such as a Strategic Vision or Transformation Strategy, and it is differentiated from the operational strategies that are used as the basis for military operations. A national military strategy must support a nation's security strategy and comply with national policy. The National Military Strategy is a document prepared by ministries and other governmental bodies with responsibilities in the defense area, and usually will not refer to public safety or national security institutions other than those subsumed within the military. All other authorities assigned with defending national interests and carrying out security-related objectives will develop their own strategies, programs, and departmental plans, and submit them for approval to the government or the parliament along with the military strategy.

Based on the prescriptions of the National Military Strategy at the Ministry of Defense level, the Resource Planning Department will issue Defense Planning Guidance (4) that represents the allocation of resources based on a planning, programming, and budgeting system. This guidance document is intended to reflect the objectives, policies, options, and strategic and operational plans that are in use in a more elaborate and dedicated manner. The Defense Planning Guidance covers the same period of time as the National Military Strategy.

The Strategic Planning Directive (5) deals with the implementation of strategic planning and also covers the same period of time as the National Military Strategy. The Joint Strategic Capabilities Plan (6) outlines the organization and deployment of the nation's forces based on the National Military Strategy.

The Acquisition and Procurement Department will develop annual plans concerning the modernization of equipment and the training of forces based on a long-term procurement strategy. At the operational level, we should mention the development of a joint doctrine within the armed forces, and at the tactical or current level the elaboration of regulations such as field manuals, dispositions, and guidelines.

\section{The Holistic Approach to Defense Policy Formulation and Implementation}

The holistic model may be best represented through examining the process of security sector reform, as shown in Figure 2. The security sector review includes all actors in the area of security, with defense being only one entity among others.

A holistic approach allows for the wide involvement of defense and other security departments in sharing responsibilities and means in accomplishing national objectives, and also of the involvement of civil society taken more broadly, in order to ensure that these civilian institutions understand their responsibilities in the area of security and their relationships with the defense community. Bringing all these actors together into a holistic framework may eliminate overlaps, fill gaps, and identify the most efficient means of dealing with any security problem. 
A defense policy builds on assumptions and national objectives depicted at the national security level and incorporated in context descriptions, identifications of security risks, and a national security policy. (It should be noted that the defense establishment, comprising policy formulation authorities, contribute actively to all these preceding processes.) After the defense policy has taken shape, the required processes - such as missions and military task assignments, capabilities and force development, and others-take place in a holistic manner, in close cooperation and coordination with other domains of the national security structure.

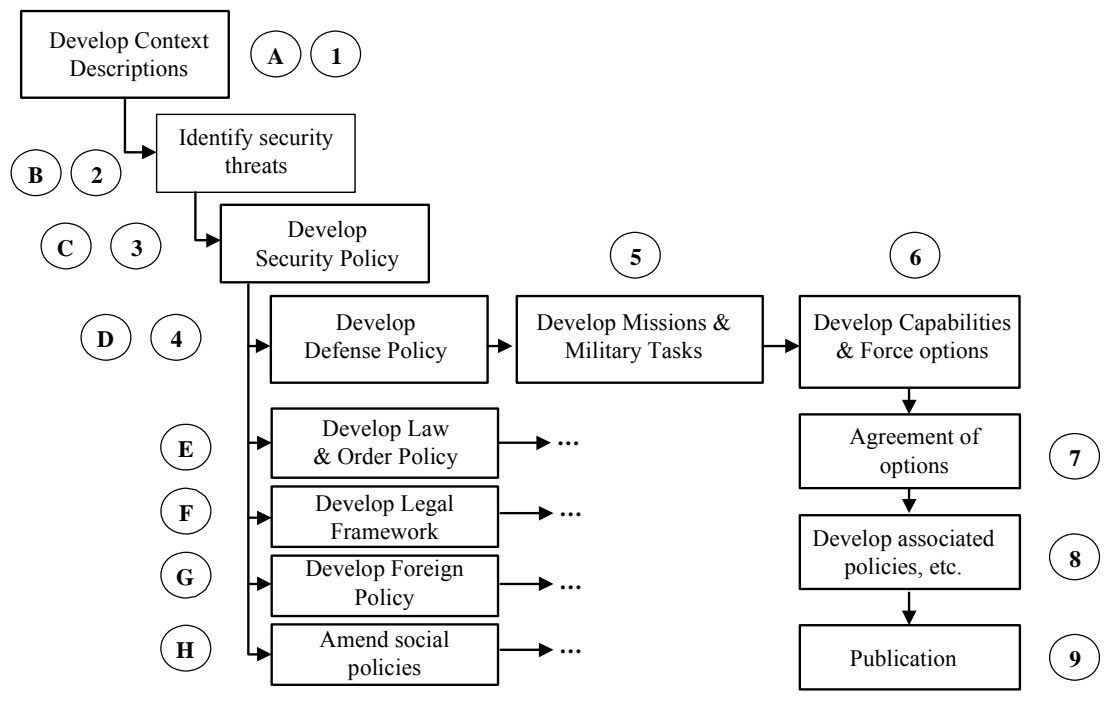

Figure 2: Security Sector Reform Process

In the first stage, context description provides an overview of the entire security environment confronting the nation. In summary, this process includes the establishment of agreed-upon views of realistic and possible scenarios within which security needs are addressed for the future. By establishing rational views of the future, unlikely extremes, which may lead to either insufficient or overstated requirements for military capabilities, can be logically eliminated in due course within the process. The process relies upon a number of drivers that have been identified as appropriate to the situation of the state. This process is a good point at which to include academics and other knowledgeable members of civil society, as well as representatives of the public, as they bring not only expertise but also credible perspectives on the position their nation may want to take in the future world.

Developing a security policy is a vital process, providing the main context for the subsequent development of departmental policies, and requiring that each area of the security sector works together in meeting strategic objectives. It builds upon an accepted understanding of the problems the state seems likely to face in the future and of 
any other desired outcomes, such as international commitments. It therefore relies not only upon the earlier steps in the process, but also upon other previously implemented policies and international agreements.

The starting point for any security policy is an assessment of threats to the nation's security; these may be of a military as well as a non-military nature. The holistic model reveals that, even if a nation's main concerns revolve around military threats, any defense policy should also look at other security threats that - while non-military in nature-require a response from the armed forces. The most obvious are civil emergencies resulting from natural or manmade disasters, such as flooding, foot and mouth disease, avian flu, or nuclear power plant accidents.

The main form in which a security policy may be embodied is a national security strategy, which in this model is a consolidated result of the processes of context description development and threat assessment. Practitioners of strategy constantly struggle to achieve a balance among many competing variables. An ancient cliché holds that strategy is an art, not a science. The true art of strategy and force planning lies in making evident how well the inevitable tensions among many variables are solved. ${ }^{5}$ Specifically, strategy is the linkage of ends and means-a "game plan" that shows how finite resources will be employed to accomplish declared objectives. Coherent strategy is the key to institutional success; it is as important for countries as it is for businesses and universities. ${ }^{6}$

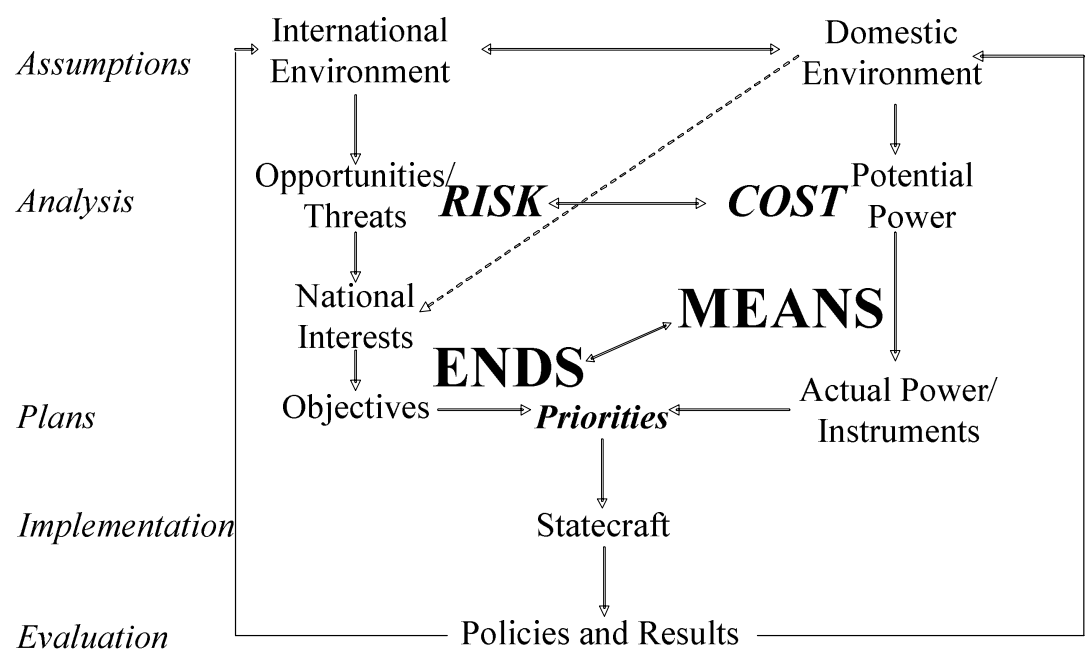

Figure 3: National Security Strategy

5 Henry C. Bartlett, G. Paul Holman, Jr., and Timothy E. Somes, The Art of Strategy and Force Planning, in Strategy and Force Planning, $3^{\text {rd }}$ ed. (Newport, RI: Naval War College, 2000), 18-34.

6 Ibid. 
The Deibel model $^{7}$ in Figure 3 presents the basic relationships that go into shaping a national security strategy, defining the classic model of ends, ways, and means. These factors include analyzing the international environment, the domestic environment, threats and opportunities, national interests, objectives, priorities, potential power, actual power reflected in instruments of power, statecraft, policies, and results.

The security policy reflected in a national security strategy will develop a statement of broad defense requirements and roles of the military and other instruments of the state in addressing identified threats, carrying out government policies, and international commitments. This security policy is shaped by the consolidated contributions of whatever is the planning and policy body at the executive level, such as a national security council; defense authorities (both military and civilian); representatives from foreign affairs, interior, finance and other ministries within the government as deemed appropriate; as well as civil society, and, of course, the legislative body.

The main process of interest in our model is the development of a defense policy based upon the strategic statement of what is the military's role in meeting the nation's security priorities, and it involves the defense policy staff, other governmental departments, and civil society, under the legal scrutiny of the parliament.

It is expected that most of the work will be undertaken by policy structures within the nation's ministry of defense. However, it should also be transparent to others as part of a continuing process, so that they may be assured that defense policy fits as expected within the overall framework of national security and other areas of national development, and that it has taken earlier work into account.

A defense policy document such as the National Defense Strategy provides a single source for further analysis of the military capabilities that are needed. In stating the threats and requirements that should be addressed by the military, defense policy provides guidance to defense establishment, including force planners. The scope of a national defense strategy is to make the armed forces of a nation and their supporting structures accountable, affordable, and efficient.

The next process is to develop options for the delivery of military capabilities against the available resources, given other demands upon the state budget and the degree of risk that is acceptable to the state. Finally, it is necessary to look at the associated policies, processes, and structures - such as finance, logistics, personnel, or public affairs - that impinge upon actions in the area of security.

Establishing optimum levels of resource allocation for defense versus the rest of the public sector is another very important issue that may be addressed in a holistic manner. Assigning relative importance to threats requiring a military response against those requiring response from other bodies is crucial when allocating resources to each component of the security sector, given that there is never enough money to satisfy everyone. These issues involve not only the classic question of how much is enough, but also

7 Terry Deibel, National Security Strategy: Fundamentals of National Security Strategy (Washington D.C.: National War College, National Defense University, 1998). 
questions about objectives; the range of capabilities that is needed, given the changes in warfare and diversity of threats; and-more important than ever-how best to use the funds available for defense. ${ }^{8}$

\section{Training Considerations}

Interactive training on defense planning within the context of defense institution building needs to be consistent both with the defense planning aspects and with the specificity of such a specialized exercise. At the outset of developing this training program we had to establish some principles for ensuring the success of such an enterprise. They are discussed briefly below, in no order of priority.

One principle was to create a fictitious situation for a case study that corresponded as closely as possible to the knowledge and experience of the participants, while avoiding giving them any basis to believe that it was inspired by any reality they know, namely by any of the nations they represented. This principle served three purposes. First, it respected the political appropriateness of not commenting on the actual situation of those nations, as it was not the aim of this exercise to discuss particular problems that any of the participants' nations might face. Second, it was a factor in minimizing the bias that may have misled the participants to focus on finding similarities with their own situational environment instead of concentrating on the tasks given within the exercise. Third, it saved a lot of the participants' scarce time that they had available to prepare themselves for the exercise and to play their assigned roles, as they were already familiar with most of the aspects presented in the situation.

Another principle was to conclude each step of the training program with a concrete product. By applying this principle, we were able to keep the participants focused on a clearly identifiable task, and they could organize their efforts more easily, as they knew from the beginning that they would have to produce a certain outcome in a given time span. Moreover, they would refer to each output later, when they were to revise their actions and outcomes, or (more importantly for us) when they were to move on to the next stage of the interactive training.

This latter observation introduces the next principle, which we may refer to as the principle of consecutive results. When designing an interactive training program, one should schedule at least three legs of the activity, in order to create an environment that allows for interaction both among the participants and among the sub-processes. It also serves the need for feedback in a simulated situation, as it models real-life situations in which organizations find themselves confronted not only with a specific situation, but also with the consequences of their previous actions and commitments. And finally, it underlines the logical sequence of events. Applying the principle of consecutive results, we may start with the first conceptual phase, such as a strategy or a policy document, and then proceed to one or two planning phases, when the outcome of the previous activity is called upon-for instance, the strategy is translated into programs, and

8 Paul K. Davis, New Challenges for Defense Planning. Rethinking How Much is Enough (Santa Monica, CA: RAND, 1994). 
resources are allocated. Then we are able to simulate the relevance of the outcome for the security environment, or for the society at large.

Another principle we sought to instill in the program was the principle of relevance. Defense institutions have to deal with numerous problems, and the defense planning process has to find solutions for each of those problems. When simulating or modeling such a situation, it is of paramount importance to choose from all those problems the most relevant ones. The relevance principle ensured that the participants were more likely to concentrate on their roles and had more incentives to cooperate in order to find solutions to a fictitious situation, since they saw that the situation was relevant for them in real life.

Another principle that is always good to keep in mind when training adults is to create incentives through competition. To satisfy this principle, at least two teams should be formed, and they should be given a fair chance to confront the competing teams' results at the end of each leg of the exercise. Not only does this create a higher motivation within each team to give their best, but it also provides an opportunity to check the validity of one's solution when confronted with another team's solution.

The last in this list of principles is the so-called do-it-yourself principle. This implies that, once the exercise had started, the role of the coordinators and advisers on the exercise staff was to keep the participants on track and within the allocated time for the task at hand, while the participants themselves were doing those tasks, with no advice from the staff on the possible solutions.

Apart from these guiding principles, the general principles of modeling were also taken into account, but we will not discuss those principles here. The only thing worth mentioning was the composition of each team (or committee) that performed during the interactive training. As the situation was fictitious, it was not at all relevant if the members of the team were from different nations or from a single nation. But, for the sake of modeling real-life experience as closely as possible, it was important that each team consisted of individuals with different backgrounds, both in terms of area of service (diplomats, civilian officials, and military) and area of expertise (strategists, planners, politicians, scientists, and practitioners).

The aim of the interactive training module was to guide the course members through a simulated process of defense policy formulation. Throughout the training activities, the participants were expected to identify the characteristics of the main documents in which the defense policy is formulated (especially a defense strategy and a defense planning directive); work in a team to achieve the basic requirements for those documents; and outline the main steps to promote such a policy to the public.

The design of such an interactive training module resulted in a set of instruments that are ready for off-the-shelf use in delivering similar courses in the future. The general design was a three-day course, and it took the format of morning plenary sessions with lectures, presentations, and discussions conducted by DCAF, and afternoon interactive training sessions conducted by the NATO Studies Center. Of paramount importance was ensuring that the morning theoretical portion was fairly consistent with the practical tasks of the afternoon. 
For the interactive training module, the NATO Studies Center published a syllabus comprising relevant information, including objectives, requirements, responsibilities, schedule, recommended readings, as well as a comprehensive scenario. The staff involved in the interactive training included an overall coordinator, activity coordinators responsible for each syndicate, and faculty advisors. Two Georgian graduates from NSC's NATO Senior Executive Master Course assisted the coordinator as faculty advisors.

There were twenty-two participants in the course, representing ministries of defense, other ministries, and non-governmental organizations from Armenia, Azerbaijan, Georgia, and the Republic of Moldova. The participants worked in two teams, with an even distribution of the represented nations and organizations.

The main instrument of the course was the scenario. It consisted of a background for a fictitious nation, named Invenzia, which included critical defense factors, national objectives and interests related to its defense, a given long-term strategic threat assessment, and the current objectives of Invenzia's armed forces. It also included openended issues related to national defense. The syllabus and scenario were available in both English and Russian; the working language of the course was Russian with translation in English, and the products were edited only in English.

The background given in the scenario revealed relevant information on Invenzia's geography, climate, population, government type, diplomacy, economy, and military sector. It also described the current status of the nation's security establishment, the main bodies of political and national power with their respective inputs on defense issues, and the actual stage of development of the nation's various defense institutions.

The critical factors for defense planning included aspects that may be found in most of the transitional nations that are members of the NATO's Euro-Atlantic Partnership Council. Just to give an example, the scenario revealed that "the delayed transition to democracy and a market economy, and the slow or even negative economic growth placed a heavy burden on the total government budget, with severe consequences for the defense budget. Most of the budget was allocated to personnel costs, under the assumption that maintaining the force as inherited from the Cold War period will safeguard the credibility of Invenzia's military power."

The open-ended issues of national defense set the scene for finding solutions based in defense policy and planning. Among those issues were:

- Is there still a need for a "total war" doctrine and its related mobilization system?

- What will be the best or the most efficient mix of active and reserve forces?

- Is conscription still a viable solution for generating interoperable and deployable forces, taking into account that all the personnel assigned for missions abroad are serving in the military voluntarily?

- Are all the military units still necessary for the new defense establishment?

- How many fighting brigades and battalions should form a highly trained, adequately equipped, rapid deployable force? 
- What is the order of priority in resource allocation between deployable and inplace forces?

- What should be the order of priority among services and within services?

- What should be the order of preference among competing capabilities?

- On a three-year implementation cycle, what would be the order of priority for resource allocation among procurement of required equipment and operating personnel training?

- What would be the time-frame for the major capabilities to be operational (namely, how many three-year cycles)?

- Is the current distribution of military bases and depots on the national territory functional and adequate to the military's new missions?

- What criteria should be used in order to prioritize the flow of resources to selected bases and depots over other bases and depots?

- Is it more cost-effective to maintain and guard depots containing obsolete weapons and ammunition or to close them down and destroy the hazardous materials?

While recognizing the importance of the theoretical portion of the course reflected in the morning lectures, we added another instrument to our toolbox in order to be certain that the participants had a common understanding of the theory they needed to use in order to accomplish their tasks. This instrument was the required readings for each of the legs of the training phase. The main requirements for those readings were that they be comprehensive, easy to grasp, that they offered references for further readings if desired and, that they were readily available under copyright regulations. There was a large array of readings that met those requirements, and we may not be certain that we picked the most relevant ones, but they were well received by the participants. ${ }^{9}$

The most challenging part of the training was related to finding solutions within the framework of a defense-planning directive. None of the participants were skilful planners, nor had they had experience in handling complex planning issues that require analytical and managerial tools. Moreover, the participants were expected to simulate in a few hours the amount of work done in several months in real life. To overcome this challenge, we introduced a generic tool, consisting of a simple computer program in spreadsheet format. This allowed the participants to generate a large number of al-

9 The required readings were: Paul K. Davis, David Gompert, and Richard Kugler: "Adaptiveness in National Defense: The Basis of a New Framework" (National Defense Institute, RAND, Issue Paper August 1996); Bruce W. Rember, "Tools for Transformation: The Military Requirements Process" (Hoover Institution, Stanford University, 2000); and Patrick J. McConnell and Lee B. Becker, "The Role of the Media in Democratization" (Athens, GA: James M. Cox Jr. Center for International Mass Communication Training and Research, University of Georgia, 2002). 
ternatives in a short period of time, dealing with resource allocation and other decisions on weighted divisions between services and budgetary chapters.

The requirements for the members of the teams were established up front in the syllabus. As the training was designed in three phases, it was clear what the desired outcomes were for each of them. In the section on defense institutions, the scenario described that Invenzia had a new National Defense Planning Act, which established clear democratic control over the nation's military and paramilitary forces. The parliament debated and authorized the National Defense Strategy issued by the president within three months from the day he took office. Based on this strategy, the Ministry of Defense issued a defense planning directive. Through this directive, the government committed itself to the implementation of the National Defense Strategy, giving clear guidance on the force structure and budgets, and on the key programs.

The first session was dedicated to drafting the National Defense Strategy of Invenzia. The participants were asked to find the most appropriate solutions to developing a credible and affordable defense, considering the national objectives and the national interests that were stated in the Strategic Vision as well as the strategic long-term assessment of the security environment.

The second session was dedicated to developing a defense planning directive in order to seek the most efficient implementation of Invenzia's National Defense Strategy, considering the required capabilities for strategic and military missions as stated in the strategy; the military modernization campaign and the new technologies available for warfare; and the budget necessary to implement the strategy.

For the final session, the participants were assigned to draft a public information plan in order to seek official approval and general public support for their defense strategy and the main guidelines on the defense planning directive.

The first interactive training session started with a plenary meeting where the course members were introduced. For the first two sessions, the participants played roles based on their own background. For the last session, they had to impersonate the public information staff in a fictitious ministry of defense. At the end of every training session, each team presented its outputs in a plenary session. The public information session also included a simulated press conference in which each team had to both take the stand and to impersonate the media.

The entire interactive training program was based on the assumption that the participants were supposed to develop specific products. The first reason was that a document — even in a summary format — was necessary to model or simulate a real-life document containing essential parts of a national defense policy. The second reason was that each session was based on the outcome of the previous one.

The products were consistent with the aim and scope of the program, and they were valuable outcomes of lively and focused discussions within the teams. Given the diversity of nations and organizations represented in the course, and the scarcity of time at the disposal of the participants, the main outlines of a national defense strategy, the subsequent defense planning directive, and the public information plan (including the press release/communiqué) were all of high quality, addressing the main issues in the scenario and finding solutions to most of the open-ended problems that had to be 
solved. In a round-table survey at the end of the interactive training program, the participants stated that they found this exercise useful; they felt that their time well spent; and they expressed satisfaction with their own performance. 
THE QUARTERLY JOURNAL

\section{Bibliography}

Bartlett, Henry, Paul Holman, and Timothy E. Somes. "The Art of Strategy and Force Planning." Strategy and Force Planning (2004): 17-33.

Davis, Paul K.. New Challenges for Defense Planning. Rethinking How Much is Enough. Santa Monica, CA: RAND, 1994.

Deibel, Terry. National Security Strategy: Fundamentals of National Security Strategy. Washington D.C.: National War College, National Defense University, 1998.

Lamb, Christopher J.. Transforming Defense In Washington, D.C.: National Defense University Press., 2005.

Lykke, Jr., Colonel Arthur F.. "Defining Military Strategy." Military Review (1997): 183-86.

McConnell, Patrick J., and Lee B. Becker. The Role of the Media in Democratization. Athens, GA: James M. Cox Jr. Center for International Mass Communication Training and Research, University of Georgia, 2002.

Rember, Bruce W.. Tools for Transformation: The Military Requirements Process. Hoover Institution, Stanford University, 2000. 